\title{
Die mag van religieuse idees
}

\author{
Jurie le Roux ${ }^{1}$ \\ Departement Ou-Testamentiese Wetenskap \\ Universiteit van Pretoria
}

\begin{abstract}
The power of religious ideas

This article focuses on Max Weber's views on the power of religious ideas. Ideas shape the world by creating groups following their own interests. Weber also illustrates how one idea (the covenant) shaped Israel into a nation and how one group (the priests) formed the Israelite society by imposing their views (which can be found in the laws) on the believing community. Closely related to ideas is a rationality by means of which Israel defined their religious identity. The article concludes with the challenge to take Weber seriously in all our Old Testament endeavours.
\end{abstract}

\section{INLEIDING}

Max Weber was lewenslank in die aard van die westerse kultuur geïnteresseerd. Hy wou weet watter sosiale kragte die weste gevorm en anders as ander samelewings gemaak het. In 1911 het hy toe 'n belangrike "ontdekking" gemaak wat sy vrou, Marianne, só verwoord het: die westerse beskawing en al sy lewensvorme is ingrypend deur 'n denkwyse en 'n leefstyl beïnvloed. Hierdie denkwyse is deur die Grieke gevorm en tydens die Reformasie met 'n bepaalde soort leefstyl "aangevul". 'n Spesifieke teoretiese en praktiese rasionalisme het dus die weste so geslyp dat "rede" en "etiek" onlosmaaklik geword het. En dit was hierdie "theoretischem und praktischem Rationalismus" wat die weste anders as die antieke sowel as die oosterse kulture gemaak het (Weber 1986:348).

En die manier waarop hierdie dubbelkantige rasionalisme die wêreld verander het, was deur middel van idees. Veral religieuse idees het Weber geboei. Volgens hom het sulke idees tot 'n sekere soort sosiale handeling aanleiding gegee en het religieuse idees mense se sosiale gedrag geslyp en

\footnotetext{
${ }^{1}$ Eers ' $n$ kort woord oor Andries Breytenbach. Een en veertig jaar gelede was ons saam eerstejaars aan die Universiteit van Pretoria. In my gedagtes sien ek hom nog as jong student en hoor ek die vrae wat hy in die klas gevra het. Van die begin af het hy indruk gemaak. Hy was tog so skrander met die tale, maar Hebreeus het in sy siel kom lê. Geen wonder dat die Ou Testament hom gegryp het en hy nou nog al sy kragte aan die Ou Testament se vertaling wy nie. Op baie maniere het Andries Breytenbach my lewe verryk en daarvoor sal ek hom altyd dankbaar wees.
} 


\section{Die mag van religieuse idees}

gerig. So was die idee van 'n Jahweverbond volgens Weber so kragtig dat dit tot die ontstaan van die volk Israel gelei het. Geen idee kan egter sonder magsbelange en -groepe oorleef nie. Sulke magsgroepe (soos die Israelitiese priesters) het idees (soos die verbond) vir hulleself toegeëien en dit tot eie voordeel en deur middel van magsmiddele (soos die Pentateugwette) laat realiseer.

Hieronder word dié gedagtes verder uitgebrei. Die artikel eindig met 'n kort omskrywing van Weber se waarde asook 'n kort voorbeeld van hoe sy denke vir die verstaan van die Pentateug se wording aangewend kan word.

\section{IDEES LAAT DIE WÊRELD DRAAI}

Alle menslike handelinge word deur idees gerig (vgl Weber 1922b:24-25, 132133). En hierdie idees is aan belang, eiebelang verbind. Idees oorleef net as dit aan werklike belange gekoppel is, want dít legitimeer belange. Wanneer sekere belange nagestreef word, moet dit deur 'n idee (of ideologie) ondersteun word. So 'n idee regverdig optrede en gee betekenis daaraan (vgl Aron 1990:202-210). Idees is daarom van werklike belange en belangegroepe afhanklik. Geen idee kan die wêreld verander of 'n samelewing slyp as dit nie mense se belange dien en nie sin aan belangegroepe se gedrag gee nie (Bendix 1962:46-47).

Dít illustreer Weber mooi in sy beroemde stelling dat die moderne kapitalisme deur die Calvinisme gevorm is (vgl Weber 1916b:536-573). Volgens hom het 'n bepaalde religieuse idee (die Calvinistiese verkiesingsgedagte) tot 'n bepaalde tipe ekonomiese gedrag (kapitalisme) aanleiding gegee. Dit was veral die dubbele uitverkiesingsleer wat Weber geboei het. Hiervolgens het God sommige tot die ewige lewe en andere tot die ewige verdoemenis verkies. Dit was 'n onmenslike leerstuk wat mense vereensaam en die gees van 'n hele geslag (in die na-Reformatoriese era) neerslagtig gestem het (Weber 1920a:84-90). Almal het oor hulle posisie gewonder. Wie was tot ewige lewe verkies en wie nie en hoe sou mens dit in elk geval ook vasstel? Op 'n merkwaardige wyse het Weber dit aan ekonomiese aktiwiteite verbind (Weber 1920a:93-116).

Volgens Calvinistiese en Puriteinse teologie kon uiterlike genademiddele (soos die sakramente) of kerklidmaatskap aan niemand geloofsekerheid verskaf nie (Kehrer 1997:124-125). Uiteindelik is die antwoord in volgehoue beroepsarbeid gevind. Dít was 'n tipiese Calvinistiese of Reformatoriese bydrae tot die westerse geestesgeskiedenis (Weber 1920a:120). Toe Luther op 'n warm dag in 1505 vir 'n donderslag geskrik het, het hy Heilige Anna, die beskermdame van sy pa se myn, beloof om 'n priester te word. In die sestiende eeu het dit 'n afgesonderde kloosterlewe 
beteken. Luther moes hom van die wêreld afkeer en sy geloof in die eensaamheid van sy kloostersel uitleef. Deel van Luther en die sestiende eeuse teologiese ontdekkings was ' $n$ totaal ander siening oor arbeid.

Beroepsarbeid het nou 'n roeping van God geword en dit moes in hierdie lewe beoefen word. Nooit weer moes dit in asketiese afsondering opgaan nie, maar moes nimmereindigend in die alledaagse lewe beoefen word (Weber 1920a:163).

En by die Puriteine het Weber hierdie besondere beroepsetiek as 't ware aan die werk gesien (Weber 1920a:163). Hulle het roepingsbewustheid, harde werk, getrouheid, spaarsin, 'n afkeer van wêreldse genietinge asook strenge Sabbatsheiliging beklemtoon. En hoe harder hulle gewerk en meer en meer geld gemaak het, was dit 'n teken van God se goeie guns. Dít het weer tot nog harder arbeid en groter geloofsekerheid gelei. Vir mistieke onttrekking was daar geen plek nie en al wat van die Middeleeuse askese oorgebly het, was "innerweltliche Askese" (Weber 1920a:118-119). Dít was 'n asketiese leefstyl (soberheid, harde werk, spaarsin) wat binne-in die wêreld gestalte gekry het. Kortom: die Calvinis en Puritein kon sy "certitudo salutis" vanuit sy ekonomiese aktiwiteite "aflees" en gemoedsrus in kapitaalvermeerdering vind. Dit was alles tekens van God se verkiesing (Weber 1920a:104, 108, 130).

Ten spyte van kritiek bly Weber se tese selfs vandag nog "one of the major landmarks of recent western intellectual history" (Parsons 1966:xx; vgl Weber 1916a:237-252). Veral ook omdat dit die noue band tussen 'n religieuse idee (uitverkiesing) en ekonomiese handelinge (kapitalisme) so skerp belig het. Dié idee kon ook slegs "oorleef" en voortbestaan omdat dit aan reële ekonomiese belange gekoppel was, deur egte mense (Puriteine) voortgedra is en uiteindelik tot werklike ekonomiese gedrag (kapitalisme) aanleiding gegee het (Le Roux 1971:30-72). Samelewings word dus dag vir dag deur die idees van magsgroepe gevorm asook verander (vgl Weber 1920b:207-236).

\section{ALLES HET BY 'N RELIGIEUSE IDEE BEGIN}

lets soortgelyk het ook in Israel se geskiedenis gebeur (Weber 1916b:8-76). Veral één idee het Israel "tot stand gebring" en één magsgroep het gesorg dat dié idee nooit sy krag verloor nie. Dit was die verbondsidee wat Israel bymekaargebring en dit was die priesters wat dié idee deur allerlei magspeletjies lewend gehou het (Weber 1913:427-474). Israel was heterogeen en het nie uit 'n homogene nomadiese groep bestaan nie. Hulle diversiteit is onder andere deur ekonomiese aktiwiteite veroorsaak. 'n Verskeidenheid aktiwiteite het tot verskillende sosiale lewensvorme en lewensideale aanleiding gegee. Die verbond het egter al dié diverse sosiale 


\section{Die mag van religieuse idees}

en ekonomiese groepe (soos herders en landbouers) bymekaargebring (Gerth \& Martindale 1960: ix-xxvii). Uiteraard het ekonomiese en politieke belange ook 'n vormende rol gespeel. Niemand sou tog die verbondsidee sonder enige ekonomiese of politieke voordeel ondersteun het nie. Israel se verbondsidee kon dus net realiseer omdat dit bepaalde sosiale belange gedien het. Of soos Weber dit gestel het: "Woher stammt nun diese Besonderheit der israelitischen Konzeption? Einige allgemeine politische Sachverhalte und ein besonderes religionsgeschichtliches Ereignis trafen zusammen, um sie entstehen zu lassen" (Weber 1921:87).

Jahwe se betrokkenheid by die verbond was deel van die magspel. Hy moes die groot verbondsidee legitimeer en begrond. Hy moes die voortbestaan van die sosiale orde asook die ordelike saambestaan van mense waarborg. Jahwe was egter ook veel meer: Hy is 'n verbondspartner gemaak. Die verbond is "nicht nur unter der Garantie des Gottes" gesluit nie, maar ook "mit dem Gott selbst als Gegenpartei" (Weber 1921:126). En as mede-verbondsgenoot is Jahwe as die "Wahlgott" voorgestel wat Israel uit eie vrye wil en uit al die ander volke gekies het en soos geen ander god beloftes aan hulle gemaak het nie (Weber 1916b:490). Dat Jahwe nie die ver-God was nie, maar 'n volwaardige verbondspartner geword het, was volgens Weber ingrypend (Weber 1921:86). Dít sou Israel se verhouding met Jahwe op 'n bepaalde manier kleur. 'n Oortreding sou nie bloot net die verbreking van 'n wet wees nie, maar 'n oortreding teen Jahwe: "Alle Verletzungen der heiligen Satzungen waren also nicht nur Verstöße gegen Ordnungen, die er garantiert, wie dies andere Götter auch tun, sondern Verletzungen der feierlichsten Vertragsverpflichtungen gegen ihn selbst" (Weber 1921:140).

Hierdie verbondsidee het ook etiese konsekwensies gehad. Dít was nogal 'n baie belangrike faset van Weber se denke oor die religieuse idee. Idees vorm mense se gedrag en leefstyl. So het die verbondsidee geheel en al die verhouding tussen Israel en Jahwe veretiseer. Alles wat met Israel gebeur het, is in etiese terme verstaan en verklaar. Alles het van die nakoming of die verwaarlosing van die verbondsverpligtinge afgehang. Alle heil en onheil is eties verklaar: ellende was die gevolg van versuim en heil die gevolg van getrouheid aan die verbond en die verbondseise (Weber 1921:8286).

Andersyds is die hele samelewing ook veretiseer. En die rede hiervoor was dat die verbond nie net met Jahwe gesluit is nie, maar ook met mekaar. Dit was 'n soort eedgenootskap tussen Jahwe en Israel asook tussen die volk onderling. En dit het die veretisering van die ganse gemeenskap meegebring (Weber 1921:313-314). Hierin het Weber radikaal van Wellhausen verskil. Vir laasgenoemde was die verbond en die veretisering van die Israel se 
lewensbestaan die gevolg van die agste en sewende eeuse profete se etiese prediking (Wellhausen 1905:415-417). Vir Weber daarenteen was die verbondsidee eerder die voorwaarde vir die etisering van die Jahwegodsdiens en die rasionalisering van die Godsbegrip (Otto 2002b:105-106). Anders gestel: die idee van 'n verbond tussen Israel en Jahwe was so kragtig dat dit as 't ware die "volk Israel" geskep het; om die verbond relevant te hou, is 'n dubbele rol aan Jahwe toegewys; Hy was die onderhouer van die verbond, maar ook verbondspartner; dít het weer tot 'n etisering van die verhouding met Jahwe asook Israel se leefwêreld gelei.

\section{IDEES, BELANGE EN BELANGEGROEPE}

Hierdie verbondsidee en die gevolglike veretisering is deur 'n sekere belangegroep ter wille van hulle eie groepsbelange gedryf. Dít was die priesters (vgl Weber 1920c:245-381). Hulle was 'n geweldige sterk magsgroep wat Jerusalem hulle magsentrum gemaak het en van daaruit gesorg het dat die verbondsidee (met sy twee onafskeidelike verbondspartners) altyd sou voortbestaan. Volgens Weber was daar twee soorte priesters. Die een was 'n vindingryke Weberiaanse skepping wat hy "sielesorgers" genoem het. Hulle was die "gevolg" van die verbondsidee en die daaropvolgende etisering van alle verhoudinge (Weber 1922b:279-285). Anders gestel: die invloed van die verbondsidee op die samelewing was dusdanig dat ' $n$ afsonderlike priestergroep "gestig" moes word. Hulle was ook priesters, maar het 'n pastorale taak gehad. Hulle was anders as die priesters wat religieus-politieke ideale nagestreef het want hulle moes die volk geestelik versorg het. Hulle moes Israel die wet leer asook op die implikasies van ontrou en getrouheid gewys het. Verder moes hulle die volk met sondebelydenis en die vergifnis gehelp het (Gerth \& Martindale 1960: xxixxvii; Otto 2002b:109-111).

Die eintlik magsfigure was egter die Jerusalemse priesters wat sterk religieuse en politieke ideale gekoester het (Weber 1921:191-199). Een so 'n religieuse ideaal was suiwerheid ten alle koste. Die suiwere verbondsvolk moes teen als wat vreemd en onbekend was, beskerm word en die magtige priesterklas sou die verwesenliking van dié ideaal verseker. So het hierdie Jerusalemse priesters gesorg dat geen kontak na $722 \mathrm{vC}$ met die mense van die ou Noordryk sou plaasvind nie. Na Samaria se val het die Assiriërs die oorblywende Israelitiese stamme met ander volke vermeng, maar die Jerusalemse priesters het geen kontak met dié "bastervolk" toegelaat nie (vgl Otto 2001a:292-294; 2001b:428-432; 2001c:587-589).

$\mathrm{Na}$ die ballingskap het die priesters hulle magsgreep versterk deur met die Perse saam te werk en te sorg dat Jerusalem die priesterlike magsentrum 


\section{Die mag van religieuse idees}

bly (Japhet 1993:66-90). Jerusalem was nie maar net 'n gewone stad nie, maar was eerder 'n magtige teokratiese stadstaat waar die tempel was en die priesters gewoon het. Hulle ideaal van suiwerheid is met nog groter mag nagestreef deur hulle geheel en al van alle nie-Judese groepe af te sonder. Veral die Samaritane moes dit ontgeld. Verskeie aanbiedinge om aan die herbou van die tempel asook die liturgie deel te neem, is verwerp. Uiteindelik het die Samaritane hulle eie pad geloop en 'n eie tempel opgerig (Albertz 1992:605-623). Die priesters se magsbeheptheid met die idee van suiwerheid het ook die plattelanders uitgesluit. Jerusalem se belangrikheid was so oorweldigend dat "buitestedelikes" uit was (Weber 1921:186-200; Otto 2002b:112-114).

Die priesters het hulle mag deur middel van die saamstel en interpretasie van Israel se wetskorpusse behou en versterk (Weber 1921:250280; 1922a:482-495). So het die Bondsboek (Eks 21-23) niks met 'n Bedoeïene of nomade kultuur te doen gehad nie, maar met priesterlike magsingryping (Weber 1921:66-77). Weber verstaan hierdie gebooie in terme van "Zweckrational" (gedrag wat 'n doel nastreef) en nie as "Werturteil" (gedrag wat deur waardes gerig word) nie. In die Bondsboek streef die "wetgewer" (die priester) na 'n bepaalde doel wat sekere belange sou dien (Weber 1922c:112). Dit gaan om die "Schutz der Gemeinfreien" en die beskerming van 'n besondere groep mense: skuldslawe, diegene wat gewelddadig (soos in 'n oorlog) verslaaf is, vrymense en slawe se huwelike, die skuldslavin se behandeling, die slaaf wat beseer word, ensovoorts. Met hierdie wette wou die priester ' $n$ bepaalde doel dien: die passifering van sosiale konflikte en die bevordering van die verbondsvolk se eenheid (Weber 1921:81, 97, 134-135; Otto 2002b:94-95).

\section{IDEES IS NOOIT LOS VAN DIE REDE NIE}

Soos hierbo genoem, het die Griekse denkstyl die weste radikaal beïnvloed (Weber 1920d:12). Weber het die oorsprong van dié rasionalisme egter by Israel gevind. Volgens Weber het die draaipunt gekom toe Israel magie verwerp het (Weber 1920a:104-106). Toe hulle die beloofde land binnegetrek het, is Israel met allerlei magiese magte en kragte gekonfronteer. Elia, Elisa en ook andere het hulle daarteen verset en uiteindelik is Baäl en die magiese vrugbaarheidsgode oorwin. Dié oorwinning se konsekwensies was verreikend. Rasionalisme het magie vervang. Plant- en oestyd het rasionele handelinge geword. Daar is rasioneel beplan wanneer geplant en geoes moes word en allerlei magiese rites is verbied (Zervit 2001:480-510). Ander sosiale handelinge soos oorlogmaak, kinders grootmaak en veral geldmaak is uit die greep van magiese kragte "verlos" en het deel van rasionele beplanning 
geword. Vir Weber was Israel se verwerping van magie ontsettend belangrik want dit het die westerse rasionalisme help slyp. Lewensfere soos die godsdiens en die ekonomie is gerasionaliseer en rasionele doelwitte is nagevolg (Weber 1920a:114-118).

Rasionalisering was vir Weber die "master conception" (Parsons 1966:xxxii) waardeur Israel sy godsdiens omskryf het en waardeur die godsdienssosioloog (lees: Ou-Testamentikus) sulke omskrywings vandag nog probeer verstaan. Vir vandag se godsdienshistorikus (lees: OuTestamentikus) beteken "rasionalisering" die intellektuele opheldering, omskrywing en sistematisering van idees. Vir Israel was rasionalisering die manier waarop hulle hulle religieuse idees kon verwerklik het. Deur voortdurende nadenke oor God, die mens en die wêreld het Israel sin aan hulle lewe gegee. En deur dié konstante rasionalisering kon hulle teenstrydighede met mekaar te versoen. So het hulle daarin geslaag om twee botsende beelde van Jahwe bymekaar te bring. Volgens Weber is Jahwe deur sommige as 'n oorlogs- en natuurgod ervaar. Oral het Jahwe angs ingeboesem en wie te naby aan Jahwe gekom het, het meteens gesterf. Aan die ander kant was Jahwe ook die "Wahlgott" wat Israel uit vrye wil en uit vele nasies gekies het. Deur voortdurende nadenke oor Jahwe as verbondspartner het die angselemente verdwyn en is die twee godsbeelde verenig (Weber 1921:127).

In die proses van etisering het hierdie rasionalisering 'n baie belangrike funksie vervul. Ellendes en swaarkry was nie meer die gevolg van magie of toorkunste nie. En die mens was ook nie meer die magtelose prooi van die gode of allerlei kragte nie. Elkeen moes verantwoordelikheid vir sy eie lewe neem en die priester-tōra was die toetssteen: ontrou of trou aan die wet het elkeen se lewenslot verseël. Vanweë hierdie rasionalisering is swaarkry as God se manier gesien om sy lieflingsvolk te tug en op te voed (Otto 2002b:121).

\section{DIE SADOKIETE EN DIE IDEE VAN DIE TORA}

Eckart Otto is waarskynlik die Ou-Testamentikus wat die meeste oor Weber gepubliseer en die waarde van sy denke vir die Ou Testament vrugbaar gemaak het. Die Ou Testament se vorming en Israel se godsdiensgeskiedenis kan ook in terme van idees en magsgroepe gelees en verstaan word. Of soos Otto dit gesê het: "Man wird dem Werk M. Webers am ehesten gerecht, indem man es nicht nur exegesierend und systematisierend reziptiert, sondern ... in einer gewandelten Forschungssituation eine neue 'Religionssoziologie des antiken Israels und Judas' schreibt'" (Otto 2002b:276). Otto se Pentateugondersoek is 'n goeie voorbeeld van so 'n Weberiaanse 


\section{Die mag van religieuse idees}

interpretasie. Dit toon hoe magsbelange en botsende idees die Pentateug gevorm en geslyp het. Hieronder word dit baie kortliks toegelig.

Volgens Otto is Deuteronomium die sleutel tot die verstaan van die Pentateug. Wie laasgenoemde wil begryp, moet dáár begin en die magspel tussen idees en die Sadokitiese belangegroepe raaksien. Hierdie Jerusalemse priesters was die intellektuele bolaag wat 'n bepaalde religieuse idee wou realiseer (Otto 2002a:57-75). Hulle is gedryf deur 'n soeke na die een wil van God wat as 'n hermeneutiese sleutel kon dien: “ ... der Einheit des Gotteswillens als hermeneutischem Schlüssel ... “ (Otto 2002b:291). Hierdie soeke het 'n lang pad met baie spanning en botsende belange gevolg. Uiteindelik het die boek Deuteronomium (asook die Pentateug) 'n lang ontwikkelingsfase deurloop en elke redaksiefase is deur ' $n$ bepaalde religieuse idee gekenmerk.

In die eerste redaksiefase was die idee van verset leidinggewend. Gedurende die sewende eeu voor Christus het die Sadokiete die konsekwensies van die neo-Assiriese koningsideologie vir Israel deurdink. Hulle het met 'n versetsaksie teen die neo-Assiriese oorheersing begin en volgens Otto hoor ons nou nog die naklanke daarvan in Deuteronomium 13:2a, 3a, 3b, 4a, 6a, 7a, 7b, 9a, 10a (Otto 1999a:57). Hierdie laat-vooreksiliese versetsteologie het die heersende Assiriese idees en motiewe in verband met staatsmag en godsdiens oorgeneem en met 'n radikaal nuwe en ander betekenis gevul (Otto 1999a:15-109; 1999b:693-696). In hierdie versetbeweging moet ons die begin van die Pentateug soek (vgl Le Roux 2001:234-244).

Tydens Deuteronomium se tweede redaksiefase het ander belange en idees weer gegeld. Dit het tydens die ballingskap gebeur toe die idee van wetsgehoorsaamheid baie prominent was en die Sadokitiese magsgroep daarom die bestaande dele van Deuteronomium herskryf het. Hulle het die laat-voor-eksiliese hervormingsprogram (Deut 6:4vv en sommige gedeeltes in 12:13-28:44) tot 'n Mosesrede omvorm (vgl Deut 5 en dele uit 9-10) wat by Horeb, die berg van God, afspeel en waartydens die dekaloog en sommige ander wette in Deuteronomium 12-26 gegee is. Volgens hierdie Sadokitiese redaksie (ook DtrD genoem) was die wet wat by Horeb gegee is, die sentrale heilsgoed van Jahwe. Gedurende die na-ballingskapse tyd het die derde Sadokitiese redaksie (ook DtrL genoem) plaasgevind. In dié tyd was die idee van die land kernbelangrik en die Sadokitiese magsgroep het Deuteronomium 1-3 en 29-30 by die bestaande Deuteronomiumboek gevoeg en dit toe met Josua verbind. Alles het nou om die land gewentel en dit is as die belangrikste gawe van Jahwe gesien (Otto 2000:196-211). 
DtrD en DtrL se botsende idees het groot spanning in die Sadokitiese priestergroepe veroorsaak (Otto 2002a:29-35). Rondom elke idee het 'n belangegroep ontstaan en elkeen het die eie belange gedien. Beide idees het ook mettertyd tot 'n Pentateuggroep en 'n Heksateuggroep aanleiding gegee. Volgens laasgenoemde, ook HexRed genoem, het die land (net soos by DtrL) sentraal gestaan en daarom is vir die Heksateug (Gen-Jos) gekies. Tussen die middel van die vyfde en die vroeë vierde eeu was daar dus 'n Sadokitiese magsgroep wat hulle rondom die Heksateug en die idee van die land geskaar het (Otto 2000:196-211, 246, 249, 250, 255, 257, 261).

Daarteenoor was daar ook 'n Sadokitiese Pentateuggroep (ook PentRed genoem) vir wie die Tōra (of Pentateug) sentraal gestaan het. Teenoor die Heksateuggroep (HexRed) se klem op land is die Tōra dus gestel (Otto 2002b:301-313) En rondom hierdie idee van die wet en die land het magsgroepe gevorm wat elkeen hulle eie belange gedien het. Uiteindelik het die idee van die wet oorwin en het die priesters van die Pentateuggroep "gewen" (Otto 2002b:276-291). Dié groep het die Pentateug toe op 'n treffende manier met die dood van Moses laat eindig (Dt 34). Die Tōra het as 't ware die leisels by Moses oorgeneem. Anders gestel: vir Moses was daar eintlik geen ander plaasvervanger as die Tōra (of Pentateug) nie. Aangrypend stel Otto dit: "Mit dem Tod des Mose wird aus der Sicht der Pentateuchredaktion der Pentateuch geboren. Mose hat den Jordan nicht überschritten, wohl aber die von inm verschriftete Töra. Mit ihr wird an seiner Stelle die Geschichte des Volk Israel weitergehen" (Otto 2000:233).

\section{WEBER SE UITDAGING}

Meer as tagtig jaar na sy dood (in 1920) bly Weber steeds vir die OuTestamentikus 'n uitdaging. Historiese arbeid kan net soveel opwindender wees indien ons Israel se religieuse idees probeer verstaan. Deur middel van dié idees het Israel sin aan eie bestaan gegee en die Ou-Testamentikus moet hierdie sinsamehange ("Sinnzusammenhänge") probeer verstaan. So iets is egter amper onmoontlik! Weber stel dit so aangrypend: die verlede is 'n onmeetlike stroom van gebeure wat aanmekaar in die oneindigheid instroom; niemand kan hierdie oewerlose stroom van konkrete gebeure keer of in woorde vasvat nie; elke historikus word telkens deur hierdie nimmereindigende gebeurestroom meegesleur sodat van finale betekenisse nooit sprake kan wees nie; elke Ou-Testamentikus word so deur hierdie ewige en onuitputlike stroom van lewensgebeure oorweldig dat Israel (of die $\mathrm{Ou}$ Testament) nooit volledig verstaan ('n egte Weberiaanse uitdrukking) kan word nie (Weber 1904:184). 
Dít is egter nie die einde van die verhaal nie. Volgens Weber kan idees ons help om kop bo water te bly en nie in historiese stroomversnellings te versink nie. Hierin lê Weber se grootheid: hy het die probleme van historiese verstaan geken, maar ons nogtans 'n "metode" (eerder 'n "model") gegee om Israel se idees uit die oorweldigende gebeuremassa los te wikkel. En dít is die beroemde "ideëeltipe". So 'n ideëeltipe is aan die een kant eensydig en aan die ander kant 'n sintese. Dit oorbeklemtoon een of meer aspekte van die werklikheid en is daarom 'n eensydige weergawe van die wêreld. Dit is verder 'n sintese omdat dit "a great many diffuse, discrete, more or less present and occasionally absent concrete individual phenomena" saambind. Al dié verskynsels word eensydig geselekteer en georden "and then blended into a unified analytical construct which is called an ideal-type" (Weber 1949:90). Wanneer die verlede met behulp van ideëeltipes bestudeer word "we are (merely) applying a purely analytical construct created by ourselves" (Weber 1949:96). Israel se "ware" geskiedenis kan dus nooit ten volle verstaan word nie en na elke poging weet ons maar nog net ten dele. En tog help Weber se ideëeltipe ons om 'n glimp op 'n vergange werklikheid te kry.

Op die skutblad van Marianne Weber se biografie oor Weber verskyn 'n gedig van Rainer Maria Rilke en die eerste versreël sê soveel: "Das war der Mann, der immer wiederkehrt ..." (Weber 1986:xiv). Oor die jare het Max Weber telkens en in verskillende gedaantes teruggekeer want tot vandag toe maak hy 'n verskil.

\section{Literatuurverwysings}

Aron, R 1990. Main currents in sociological thought, 2. London: Cox \& Wyman. Bendix, R 1962. Max Weber: An intellectual portrait. New York: Doubleday.

Gerth, H \& Martindale, D 1960. Preface Weber, in Weber, M, Ancient Judaism, ixxxvii. Illinois. IL: The Free Press.

Japhet, S 1993. I \& II Chronicles. London: SCM Press.

Kehrer, G 1997. Max Weber (1864-1920), in Michaels, A (Hrsg), Klassiker der Religionswissenschaft, 121-132. Darmstadt: Wissenschaftliche Buchgesellschaft.

Le Roux, J H 1971. 'n Godsdienssosiologiese ontleding van Max Weber se stelling dat Protestantisme verantwoordelik is vir kapitalisme. MA-verhandeling, Universiteit van Pretoria, Pretoria.

Le Roux, J H 2001. 'n Nuwe kyk op die Pentateug. NGTT 14(3), 234-244.

Otto, E 1999a. Das Deuteronomium, 15-109. Berlin: Walter de Gruyter.

Otto, E 1999b. Deuteronomium. RGG 4(II), 693-696.

Otto, E 2000. Das Deuteronomium im Pentateuch und Hexateuch. Tübingen: Mohr.

Otto, E 2001a. Art. Israel II. Geschichte, 2. Kulturgeschichte. RGG4VI, 292-294.

Otto, E 2001b. Art. Jerusalem I. Altes Testament, $R G G^{4}$ IV, 428-432.

Otto, E 2001c. Art. Josia/Josiareform, RGG4 IV, 587-589.

Otto, E 2002a. Gottes Recht als Menschenrecht. Rechts- und literaturhistorische Studien zum Deuteronomium. Wiesbaden: Harrasowitz Verlag. 
Otto, E 2002b: Max Webers Studien des Antiken Judentums. Tübingen: Mohr.

Parsons, T 1966. Introduction, in Weber, M, Sociology of religion, xix-Ixvii. London: Methuen.

Shils, E A 1949. Foreword, in Weber, M, The methodology of the social sciences iii-x. New York: The Free Press.

Weber, M 1904. Die "Objektivität" sozialwissenschaftlicher und sozialpolitischer Erkenntnis, in Schriften zur Wissenschaftslehre, 146-214. Tübingen: Mohr. (Digitale Bibliothek Band 58: Max Weber. Berlin: Direct Publishing.)

Weber, M 1913. Ueber einige Kategorien der verstehenden Soziologie, in Gesammelte Aufsätze zur Wissenschaftslehre, 427-474. Tübingen: Mohr. (Digitale Bibliothek Band 58: Max Weber. Berlin: Direct Publishing.)

Weber, M 1916a. Die Wirtschaftsethik der Weltreligionen: Einleitung, in Gesammelte Aufsätze zur Religionssoziologie I, 237-252. Tübingen: Mohr. (Digitale Bibliothek Band 58: Max Weber. Berlin: Direct Publishing.)

Weber, M 1916b. Die Wirtschaftsethik der Weltreligionen: Zwischenbetrachtung. Theorie der Stufen und Richtungen religiöser Weltablehnung, in Gesammelte Aufsätze zur Religionssoziologie I, 536-573. Tübingen: Mohr. (Digitale Bibliothek Band 58: Max Weber. Berlin: Direct Publishing.)

Weber, M 1920a. Die protestantische Ethik und der Geist des Kapitalismus, in Gesammelte Aufsätze zur Religionssoziologie I, 17-206. Tübingen: Mohr. (Digitale Bibliothek Band 58: Max Weber. Berlin: Direct Publishing.)

Weber, M 1920b. Die protestantischen Sekten und der Geist des Kapitalismus, in Gesammelte Aufsätze zur Religionssoziologie I, 207-236. Tübingen: Mohr. (Digitale Bibliothek Band 58: Max Weber. Berlin: Direct Publishing.)

Weber, M 1920c. Religionssoziologie: Typen religiöser Vergemeinschaftung, in Wirtschaft und Gesellschaft, in Wirtschaft und Gesellschaft, 245-381. Tübingen: Mohr. (Digitale Bibliothek Band 58: Max Weber. Berlin: Direct Publishing.)

Weber, M 1920d. Vorbemerkung, in Gesammelte Aufsätze zur Religionssoziologie I, 1-17. Tübingen: Mohr. (Digitale Bibliothek Band 58: Max Weber. Berlin: Direct Publishing.)

Weber, M 1921. Das Antike Judentum, in Gesammelte Aufsätze zur Religionssoziologie III, 1-400. Tübingen: Mohr. (Digitale Bibliothek Band 58: Max Weber. Berlin: Direct Publishing.)

Weber, M 1922a. Rechtssoziologie, in Wirtschaft und Gesellschaft, 387-513. Tübingen: Mohr. (Digitale Bibliothek Band 58: Max Weber. Berlin: Direct Publishing.)

Weber, M 1922b. Religionssoziologie: Typen religiöser Vergemeinschaftung, in Wirtschaft und Gesellschaft, 245-381. Tübingen: Mohr. (Digitale Bibliothek Band 58: Max Weber. Berlin: Direct Publishing.)

Weber, M 1922c. Soziologische Kategorienlehre, in Wirtschaft und Gesellschaft, 73630. Tübingen: J C B Mohr. (Digitale Bibliothek Band 58: Max Weber, S. 1401. Berlin: Direct Publishing.)

Weber, M 1949. The methodology of the social sciences. New York: The Free Press. Weber, Marianne 1986. Max Weber: Ein Lebensbild. 3.Aufl. Tübingen: Mohr. (Digitale Bibliothek Band 58: Max Weber. Berlin: Direct Publishing.)

Wellhausen, J 1905. Prolegomena zur Geschichte Israels. Berlin: Georg Reimer. Zevit, Z 2001. The religions of ancient Israel. New York: Continuum. 